\title{
MELANIE KLEIN, UNA PRI NCESA QUE CREÓ SU PROPIO REINO
}

MELANI E KLEI N A PRINCESS WHO CREATED HER OWN KI NDDOM

\section{RESUMEN}

Las formulaciones kleinianas no pueden ser encuadradas como un mero desarrollo del psicoanálisis freudiano, dado que suponen cambios radicales en su metapsicología, núcleo intocable del sistema. En todo caso, Melanie Klein merece un lugar de privilegio entre las mujeres pioneras que aportaron ideas originales a la psicología del inconsciente y aunque siempre se autoconsideró una fiel seguidora de Freud, terminó desarrollando su propio reino.

Palabras claves: Melanie Klein, Psicoanálisis freudiano, Relaciones objetales, «Instinto» de muerte, Posición esquizoparanoide, Posición depresiva, Complejo de Edipo temprano, Superyó precoz.

\section{ABSTRACT}

Melanie Klein's formulations should not be framed as a mere development of Freudian Psychoanalysis. In fact, they represent a radical change in his methapsychology, the otherwise known, as an untouchable core of the system. Nevertheless, Melanie Klein deserves to have a privileged position among those female psychoanalysts who, in one way or another, contributed with original ideas to the psychology of the unconsciousness. Although, she always considered herself simply as a Freud's follower, she ended up developing her own reign of knowledge.

Keywords: Melanie Klein, Freudian Psychoanalysis, Object relationship, Death I nstinct, Schizo-paranoid position, Depressive position, Early Oedipus Complex, Praecox Superego. 


\section{NTRODUCCIÓN}

Aunque las teorías de Melanie Klein nacieron del cuerpo teórico-técnico creado por Sigmund Freud, Ilegaron a revolucionar la metapsicología tradicional, dándole a sus conceptos centrales matices muy peculiares, lo que obliga a encuadrarlas como una doctrina psicoanalítica particular.

En el surgimiento de las ideas kleinianas hay que recordar el Simpósium sobre análisis infantil que tuvo lugar en mayo de 1927 en la Sociedad Psicoanalítica Británica, donde se mantuvo una dura polémica en torno a las opuestas perspectivas de Melanie Klein y de Anna Freud, que en su Introducción a la técnica del análisis de niños destacaba que la conducta infantil en la situación analítica estaba fundamentalmente mediatizada por los hechos vividos en la realidad presente con los padres, en especial en lo tocante a sus aspectos negativos, pensando que era imposible que un chico pequeño estableciera una genuina transferencia, calificando de silvestre el trabajo analítico de Klein, ya que ésta, en un contexto de juegos inocentes y no en el de las asociaciones libres, utilizaba interpretaciones profundas sobre falsos fenómenos transferenciales (1).

El posicionamiento de Anna Freud se situaba en la línea abierta por Hermine von Hug-Hellmuth, que en un trabajo de 1920, titulado Sobre la técnica del análisis infantil, insistió en la función educativa del psicoanálisis en la niñez, propugnando que a través del mismo debían inculcarse valores morales, estéticos y sociales (2), lo que fue absolutamente rechazado por Klein que asumió la posibilidad de un análisis en toda regla del niño pequeño (3). Ha de tenerse en cuenta en todo caso que para Klein la transferencia, esencial para un trabajo analítico, no suponía la reedición de una pasada neurosis infantil, como se entiende en el modelo freudiano, sino la impregnación de las relaciones de la vida ordinaria (relaciones con los objetos externos) con productos procedentes de la fantasía inconsciente que ocasionaba la realidad subjetiva (relaciones con los objetos internos), lo que sería válido tanto para el niño como para el adulto, aconteciendo lo patológico cuando tiene lugar una invasión excesiva de la fantasía interna inconsciente en la vida externa (4). Por otro lado, la técnica del juego, y el soporte teórico que implica, lo consideró un elemento sustitutivo de la asociación libre de ideas que podía tener lugar en los adultos y no en los pequeños (5).

Aunque en el terreno técnico se produjo con el paso del tiempo un cierto acercamiento entre Anna Freud y Melanie Klein, aceptando aquélla la posibilidad de tratar niños antes del período de latencia y emplear el juego como un instrumento técnico, como puede verificarse en la versión de 1946 de su Introducción a la técnica del análisis de niños, que apareció entonces con el título de Psicoanálisis de niños (6), en el campo teórico, por el contrario, el alejamiento entre ambas se fue acusando progresivamente, sobre todo después de que Klein concretara definitivamente sus teorías de las posiciones y de las relaciones objetales precoces, a partir de mitad de la 
década de los años cuarenta, dado que con esto dejaba de lado el tradicional complejo de Edipo como fuente central del desarrollo normal y patológico en favor de la Ilamada posición depresiva y situaba la aparición del yo y superyó muy precozmente, además de darle una prioridad total a la pulsión tanática sobre la erótica. Todo ello abocó, en tales fechas, a grandes controversias en el seno de la Sociedad Psicoanalítica Británica, lo que desembocó en la constitución en la misma de dos grupos de formación, uno con los seguidores de Anna y otro con los afines a Melanie (7). A partir de entonces la escuela kleiniana se autonomizó en el seno de dicha Sociedad, aunque hacia la mitad de la década de los cincuenta, empezaron algunas deserciones a causa de las divergencias respecto al papel de lo constitucional en el desarrollo y en la psicopatología y más concretamente en cuanto al protagonismo de la envidia innata; así mismo tampoco había acuerdo en lo tocante a la función de la contratransferencia y las subsiguientes intervenciones del terapeuta.

Desde entonces el psicoanálisis kleiniano tomó un doble camino: algunos discípulos siguieron relativamente fieles a Klein, los poskleinianos propiamente dichos (Bion, Meltzer, Bick y otros, mientras que el llamado grupo británico (Fairbairn, Balint, Guntrip y Winnicott) se alejó bastante de la matriz original, dando un papel de suma importancia a los traumas psicológicos acontecidos en la relación objetiva del bebé con su madre, además de conceder al comportamiento del terapeuta, en el curso del análisis, una función esencial a la hora de aliviar o resolver las consecuencias de tales traumas.

\section{ESBOZO BI OGRÁFICO DE MELANI E KLEIN (1882-1960)}

Melanie Klein (de soltera Reizes) nació en Viena el 30 de marzo de 1882, en el seno de una familia centroeuropea de origen judío. Su padre, Moriz Reizes era médico general y dentista. Su madre, Libussa Deutsch, tenía veinticuatro años menos que su marido, del que tuvo cuatro hijos, Emile (que murió con veinticinco años, agotado por el alcohol, la droga y la pobreza), Emanuel, Sidonie (que falleció con ocho años de tuberculosis) y Melanie.

Melanie, tras tener que dejar de lado su intención de estudiar medicina a causa de su noviazgo con 17 años y casamiento a los 21 (contrajo matrimonio el 31 de marzo de 1903), estudió Arte e Historia en la universidad de Viena, pero sin llegar a graduarse en nada (8).

Su acercamiento al psicoanálisis fue por razones terapéuticas personales, dado que aquejaba intensas y prolongadas depresiones, teniendo incluso que ser ingresada en diversas casas de salud por este motivo. Sus estados depresivos estaban de alguna manera conectados con su fracaso matrimonial, acusándose tras la muerte de la madre, con la que había mantenido una relación muy ambivalente. Parece ser, en todo caso, que fue decisivo en su búsqueda del psicoanálisis la lectura del ensayo 
freudiano Sobre el sueño cuando ya vivía en Budapest y habían nacido sus tres hijos (Melitta en 1904, Hans en 1907 y Erich en 1914).

No hay precisión sobre cuándo llevó a cabo su primer análisis personal con Sàndor Ferenczi, situándolo Grosskurth (8) desde finales de 1914 hasta 1919, mientras que Petot (9) refiere que debió transcurrir durante el año 1916 y principios de 1917, para ser reanudado en mayo de 1917 (a mediados de febrero Ferenczi enfermó de tuberculosis pulmonar, ingresando en un sanatorio cercano a Viena). Dicho tratamiento terminó por convertirse en su primer período de formación psicoanalítica, asistiendo en 1918 como invitada al V Congreso Psicoanalítico Internacional, celebrado los días 28 y 29 de septiembre en Budapest, donde vio por vez primera a Sigmund Freud (10).

Ferenczi animó a Melanie a que se ocupase del campo psicoanalítico infantil, iniciando ésta tal labor con su propio hijo Erich (Fritz), pero sólo con intenciones pedagógicas y preventivas, sirviéndole este trabajo de base para la disertación de presentación que llevó a cabo en la Asociación Psicoanalítica Húngara el 13 de julio de 1919, cuyo contenido fue publicado parcialmente a finales de 1920 con el título de La novela familiar 'in statu nascendi' y más tarde en una versión completa, pero corregida (ocultando la identidad del hijo), bajo el título El desarrollo de un niño (11).

En un momento dado Klein viró, incluso ya con Fritz, hacia compromisos claramente analíticos, siguiendo sugerencias de Anton von Freund (12), tarea que continuó tras asentarse en Berlín a partir de enero de 1921, a donde acudió para llevar a cabo un segundo análisis personal con Karl Abraham y contactar con un grupo en donde era bastante activo el interés por el psicoanálisis de niños.

En 1922, Klein se integra como miembro asociado en la Asociación Psicoanalítica de Berlín, llegando a ser titular el 23 de febrero de 1923. El año siguiente, inicia su análisis con Abraham, tratamiento que dio fin al cabo de catorce meses, por una grave enfermedad de Abraham, que finalmente falleció en diciembre de 1925. Por estos años también se produce su divorcio (entre 1925 y 1926), aunque su marido vivía en Suecia desde el otoño de 1919. Klein, sin embargo, ha referido en ocasiones que el divorcio tuvo lugar en 1922 (otras veces afirma que ocurrió en 1923), quizás para justificar su conducta en este tiempo (8). En abril de 1924 se casa su hija Melitta con Walter Schmiedeberg, catorce años mayor que ella, la cual le dio a partir de un momento dado muchos problemas, llegando a enfrentársele violentamente en algunas conferencias y sesiones clínicas.

En Berlín, Klein analiza a una niña que ha pasado a ser famosa en la literatura psicoanalítica, Rita, así como a otros niños pequeños, cuyos casos están recogidos en El psicoanálisis de niños (13), sin que se mencionen en esta obra los tratamientos con sus hijos, los cuales aparecen en otras publicaciones con los pseudónimos que indicamos entre paréntesis. 
La inesperada muerte de Karl Abraham y la animosidad contra el análisis infantil que apareció en algunos de los psicoanalistas berlineses, tras el desgraciado hecho del asesinato de Hug-Hellmuth en 1924 por parte de su sobrino Rolf, de 18 años, hijo de Antonia, una hermanastra de Hermine (14), junto a la invitación que Ernest J ones le había hecho, en el Congreso de Salzburgo en abril de 1924, para que diera en Londres un ciclo de conferencias (que dictó durante el verano de 1925), provocó en Klein un nuevo y definitivo cambio de residencia, dejando Berlín en octubre de 1925 para asentarse en la capital británica el año siguiente, dado que Jones le había solicitado que tratase a sus hijos.

Las primeras formulaciones teóricas de Klein fueron bien acogidas en la Sociedad Psicoanalítica Británica, lo que Edward Glover (15) justifica porque los psicoanalistas británicos experimentaban un sentimiento de inferioridad con respecto a sus propias contribuciones, porque los puntos de vista de Klein eran enérgicamente sustentados por Jones, figura muy prestigiada, y porque las ideas kleinianas incluían gran cantidad de sugerencias originales que iluminaban ciertos problemas del desarrollo temprano que las teorías clásicas no resolvían. No obstante, lamentablemente pronto surgieron fuertes enfrentamientos en el seno de la Sociedad Psicoanalítica Británica, cosa que obligó a que se organizaran dos grupos de formación, uno constituido por los partidarios de Anna y otro por los de Melanie, lo que paradójicamente favoreció la institucionalización de la escuela kleiniana, que se mantuvo con mucha fuerza hasta 1957, año en que se publica Envidia y gratitud, donde Klein mantiene la tesis de la existencia de una envidia constitucional en el ser humano, defendiendo que este sentimiento sería la base primaria de las relaciones objetales y de la psicopatología (16). Esto, junto a las discrepancias respecto a la importancia técnica de la contratransferencia, ocasionó el abandono de algunos de sus más fieles discípulos, tal como Paula Heimann.

La obra de Klein es extensa e intensa, debiéndose destacar El psicoanálisis de niños (1932), donde sistematizó el contenido teórico que había venido gestando desde 1919, de entre lo que ha de resaltarse también los trabajos El desarrollo de un niño (1921), Análisis infantil (1923), Principios psicológicos del análisis infantil (1927), Estadios tempranos del conflicto edípico (1928), La personificación en el juego de los niños (1929) y La importancia de la formación de símbolos en el desarrollo del yo (1930), conjunto que está recogido en Contribuciones al psicoanálisis (Klein, 1948) y en el primer tomo de sus Obras Completas (Klein, 1975). Con posterioridad, desde 1932 a 1948, Klein formula con mayor precisión y amplitud su teoría de las posiciones y sus ideas revolucionarias sobre el complejo de Edipo, además de delimitar los conceptos de fantasía infantil, escisión e identificación proyectiva, aportaciones que aparecieron en los artículos Contribución a la psicogénesis de los estados maniacodepresivos (1935), Amor, odio y reparación (1937), El duelo y su relación con los estados maniaco-depresivos (1940), El complejo de Edipo a la luz de las ansiedades 
tempranas (1945), Notas sobre algunos mecanismos esquizoides (1946) y Sobre la teoría de la ansiedad y la culpa (1948), la mayor parte de los cuales están incluidos en Desarrollos en psicoanálisis (Klein, Heimann, I saacs y Riviere, 1952) y en el primer y tercer tomos de sus Obras Completas.

Finalmente, desde los años cincuenta hasta su muerte, Klein centra su trabajo teórico en la envidia primaria, ocupándose también de ciertos componentes de la técnica, pudiendo recordarse al respecto los artículos Sobre los criterios para la terminación de un psicoanálisis (1950), Los orígenes de la transferencia (1952), Algunas conclusiones teóricas sobre la vida emocional del bebé (1952), La técnica psicoanalítica del juego: su historia y significación (1955), Sobre la identificación (1955), así como los libros Envidia y gratitud (1957), Nuestro mundo adulto y sus raíces en la infancia (1959), Sobre el sentimiento de soledad (1959), Las emociones básicas del hombre (1960) y la obra póstuma Relato del psicoanálisis de un niño (1961).

De entre la amplia bibliografía sobre la doctrina kleiniana han de citarse también Nuevas direcciones en psicoanálisis (Klein, Heimann, Money-Kyrle y otros, 1955), los ensayos de Hanna Segal Introducción a la obra de Melanie Klein (1964) y Melanie Klein (1979), La obra de Melanie Klein, 2 tomos (Valle, 1979, 1986), Melanie Klein. Primeros descubrimientos y primer sistema (1919-1932) (Petot, 1979), la biografía Melanie Klein. Su mundo y su obra (Grosskurth, 1986), Melanie Klein: cierre y apertura (Valle, 1999) y por supuesto las Obras Completas de Melanie Klein, 4 tomos (1975), editadas en inglés por Hogarth Press y el Instituto de Psicoanálisis, habiendo aparecido en castellano entre 1987 y 1990, bajo la responsabilidad de Paidós.

\section{LAS REVOLUCIONARIAS TEORÍ AS DE MELANIE KLEIN}

La obra de Klein nació de la observación clínica dentro de un encuadre psicoanalítico particular, establecido para facilitar la conducta espontánea de los niños, valiéndose sobre todo del instrumento dado por el juego libre con determinados objetos preparados ad hoc y de las concomitantes verbalizaciones de los chicos, así como de los dibujos que éstos realizaban en el curso del tratamiento (17). En este encuadre los pequeños ponían en marcha una rica y compleja fantasía, que contenía la expresión de variadas temáticas pulsionales (especialmente agresivas) conectadas a los objetos significativos para el niño (tanto objetos internos como externos), con la consiguiente ansiedad y la necesidad de una serie de defensas para su control. Estos hechos exigían, para su explicación, de la presencia de un yo y un superyó precoces, capaces de elaborar tales procesos, lo que obligaba a apartarse de los presupuestos metapsicológicos freudianos, donde tales instancias se consideraban de aparición más tardía.

La hipótesis central kleiniana mantiene que si bien lo psíquico nace desde lo instintivo (sobre todo del «instinto» de muerte y sus derivados), su máxima expre- 
sión acontece en la fantasía (phantasy), donde se muestran las relaciones que el yo infantil establece con sus objetos internos, cosa que determina en un grado mayor 0 menor las posteriores relaciones con los objetos externos, sin que a lo que realmente suceda 0 haya sucedido en la interacción con éstos se le dé especial importancia. Dado el carácter destructivo de tal fantasía por la presencia predominante de la pulsión de muerte y la acción de un superyó muy sádico, se sobreañade una intensa ansiedad, que necesita de la acción de particulares defensas puestas en marcha por el yo. Todo este conjunto permite el establecimiento de unas peculiares relaciones tanto con los objetos internos como con los objetos externos, marcando dos posiciones básicas, la posición esquizoparanoide y la posición depresiva (5). A partir de ello, según Klein, se van conformando dos núcleos peculiares en el psiquismo humano, dependiendo su destino caracterial y conductual de cómo se controlen y resuelvan las ansiedades que tienen lugar cuando el niño se desenvuelve en tales posiciones básicas (18).

En cuanto a la angustia, motor básico del desarrollo humano, supone un producto que nace de la acción de un superyó, igualmente precoz (que no es asumido por los freudianos), que, por así decir, recrimina cruel y severamente los deseos sádicos presentes en las fantasías, obligando a la transformación defensiva de esos deseos por parte del yo. En este marco, la ansiedad es explicada por Klein como un producto del temor a la retaliación (ojo por ojo, diente por diente), dado el sadismo infantil presente: los objetos atacados se transforman en objetos vengadores, tanto desde fuera (el objeto malo externo) como desde dentro (el objeto malo interno, primer núcleo del superyó) (19).

Un concepto central de la doctrina kleiniana es el de posición. Este término no es equivalente a etapa o fase, implicando una configuración específica de relaciones con los objetos, así como ciertas ansiedades y defensas, configuración que persiste de alguna forma a lo largo de toda la vida, a diferencia de la etapa o fase que es algo transitorio: la inicial posición esquizoparanoide nunca es completamente reemplazada por la posterior posición depresiva, mostrando una y otra su presencia durante toda la vida del sujeto, fundamentalmente a través de las manifestaciones de la ansiedad paranoide y de la ansiedad depresiva, respectivamente. Ahora bien, si el desarrollo ha sido adecuado, ambas angustias se irán atemperando y modificando favorablemente.

Klein $(20,21)$ describió primero la posición depresiva y con posterioridad la posición esquizoparanoide, conformando todo ello la teoría de las posiciones, que incluye una peculiar conceptualización de las relaciones que el sujeto establece con sus objetos internos y externos (teoría de las relaciones objetales). Según Segal (18), la posición esquizoparanoide (primero denominada por Klein posición paranoide y luego por influencia de Fairbairn posición esquizoparanoide) se caracteriza por el hecho de que el bebé no reconoce el objeto total (la madre como una persona), sino 
que por la acción de la escisión (splitting) se crean dos objetos parciales (prototipo de los cuales es el pecho materno), uno estimado como bueno y otro como malo, aunque en ocasiones patológicas hay más de dos objetos. A esta defensa precoz se suman en un momento dado otras, como la identificación proyectiva, la negación mágica omnipotente y la idealización (22).

Cuando el bebé llega a reconocer a la madre como un objeto total, estará ya conformando la posición depresiva, donde predominan la integración, la ambivalencia, la culpa y la ansiedad depresiva, así como una serie de defensas específicas, como la reparación (maníaca y no maníaca) y otras, además de las, ya más organizadas, defensas de la posición esquizoparanoide.

Para Klein, pues, el conflicto intrapsíquico no es fruto del enfrentamiento entre el deseo pulsional y la defensa (o entre el ello y el yo/superyó), sino más bien una encarnizada lucha entre las pulsiones de amor y odio respecto a los objetos, lo que aboca en el establecimiento de las dos posiciones básicas del primer año de la vida, las cuales quedan definidas por sus particulares deseos, ansiedades y defensas, conduciendo a unas específicas fantasías, que expresan las más variadas conflictivas tanto con los objetos internos como con los externos. En tal marco, el complejo de Edipo es aceptado como un elemento que aparece en la posición depresiva, de forma que la estructura delimitada por Freud en la fase fálica no sería sino una expresión tardía del mismo. Además, se mantiene que el superyó es previo a tal complejo, al contrario de lo que Freud había expresado.

La construcción fuera de la mente del bebé, es decir en la realidad externa, de un objeto ideal y de un objeto persecutorio, se ocasiona por la acción de la escisión, la desviación y la proyección, con el fin de atemperar la angustia. En un momento dado, tales objetos parciales externos serán introyectados con fines defensivos, creándose así los primeros esbozos del superyó, los cuales han de ser considerados como especie de objetos internos (23).

Sobre la base de la proyección de las propias partes malas en uno de los objetos parciales, el bebé sentirá a una porción de su madre (habitualmente el pecho) como destructiva y perseguidora, de forma que la primitiva ansiedad frente a la propia pulsión de muerte se transforma en ansiedad persecutoria, lo que trata de controlar por medio de la agresividad con que el yo infantil se quedó en parte tras la proyección parcial de la pulsión tanática. Lo mismo acontece con la pulsión erótica, de forma que el niño se relacionará en su fantasía con objetos internos y externos tanto buenos como malos, los cuales constituyen una especie de fantasmas (23).

Paulatinamente, en el curso del desarrollo, se producirá una integración de los fantasmas externos, por un lado, y de los fantasmas internos, por otro. Además, la introyección del objeto bueno fortalecerá el incipiente self (que es asimilable al unomismo, como el cuerpo, el yo como instancia del aparato psíquico, etc., en oposición a lo que no lo es) y aumentará la tolerancia a la ansiedad, dejando de ser precisa la 
proyección de lo destructivo propio, con la consiguiente disminución de la ansiedad persecutoria, favoreciéndose de esta forma las integraciones que acontecerán en la inmediata posición depresiva, la cual se superpone en sus inicios con los momentos finales de la posición esquizoparanoide.

Las características de la posición esquizoparanoide exigen, para su mejor entendimiento, de la aclaración de la función de otras dos defensas: idealización y negación mágica omnipotente. La primera se caracteriza por un aumento exagerado de los rasgos positivos y protectores del objeto parcial bueno, sirviendo tal defensa como elemento compensador de la ansiedad persecutoria. En Envidia y gratitud (15), la función de la idealización se amplía considerablemente, entendiéndose como una tendencia inherente al ser humano a buscar la gratificación perfecta, debiéndose tener en cuenta que desde entonces la envidia es considerada por Klein como un sentimiento innato relacionado con el hecho de creer en la existencia de un pecho extremadamente bueno que se desea destruir a toda costa. La negación mágica omnipotente, cuando actúa en el proceso defensivo para contrarrestar la angustia autodestructiva y la angustia persecutoria, tiene como misión el quitar de en medio las fantasías cargadas de temáticas dañinas contra el sujeto, lo que aboca en una especie de estado maníaco (precisamente por efecto de las defensas omnipotentes y mágicas), del que antes 0 después habrá que salir, si es que el desarrollo sigue una línea sana.

En cuanto a la posición depresiva, supone una nueva organización de la vida mental del bebé, implicando las claves para el logro de la salud mental. Sus notas características, son $(20,21)$ : a) una particular ansiedad culposa sostenida por los presuntos daños realizados al objeto (ansiedad depresiva); b) una relación en la que el objeto externo ya no es parcial, sino total, dándose paralelamente una integración en el self y en los primitivos objetos internos; y, c) un predominio de la defensa llamada reparación, que se hace presente cuando es apropiada la evolución de las conflictivas de esta posición y de la esquizoparanoide.

Aunque en la instauración de la posición depresiva son necesarias ciertas experiencias gratificantes con el objeto externo y que tales hechos predominen sobre los frustrantes, para Klein lo que más cuenta está en las condiciones internas y constitucionales, como son los potenciales relativos de la pulsión erótica (gratitud) frente a los potenciales de la pulsión tanática (envidia). En todo caso, si el yo infantil se percata, por así decir, de la mayor fuerza del objeto ideal respecto al objeto persecutorio y del predominio de la pulsión de vida sobre la pulsión de muerte, tales circunstancias conducen a una identificación del yo con el objeto ideal, aumentando las posibilidades para enfrentarse a la ansiedad persecutoria sin tener que echar mano de defensas inadecuadas, como la escisión patológica y otras.

La paulatina disminución de la ansiedad paranoide permite la integración del self y de los objetos internos y externos, disminuyendo la necesidad de las proyecciones 
defensivas, todo lo cual va facilitando una mejor distinción entre dicho self y el objeto externo, estableciéndose la imprescindible identidad. Consiguientemente, a lo largo de la posición depresiva no predomina la protección narcisista del self, sino de los objetos externos e internos, teniendo lugar un enfrentamiento constante entre el amor y el odio. Ello permite un cambio en la vivenciación de la realidad subjetiva y objetiva, reconstruyéndose la integridad de los objetos que habitan en ambos espacios, dejando de ser percibidos tales objetos como parciales, apareciendo la tolerancia al dolor psíquico y el aumento del control de los impulsos agresivos.

Todo ello se favorece gracias a la simbolización, proceso que Klein conecta con la elaboración del duelo (21): el objeto perdido crea un duelo, que se resuelve por medio del reemplazo de aquél por sustitutos simbólicos (pensamientos, recuerdos, etc.). Ahora bien, el primer paso mediante el que se trata de superar la ansiedad depresiva es por la acción de las denominadas defensas maníacas: triunfo, control omnipotente y desprecio en las relaciones con el objeto (18). J unto a tales defensas actúa la reparación, permitiendo la reconstrucción y superación de la posición depresiva. Y, si no es así, acontecerá una regresión a la posición esquizoparanoide, o bien se instaurará un núcleo defensivo de naturaleza depresiva, lo que dará la cara en forma de psicosis esquizofrénica o psicosis maniaco-depresiva en un momento dado de la vida.

Lo descrito se acompaña de nuevas ansiedades, derivadas de la creencia de que los propios impulsos agresivos presentes hayan destruido o lleguen a destruir al objeto amado, del que tanto se depende. Tal dependencia se acrecienta en la posición depresiva, al captar el niño que el objeto, por su autonomía, puede alejarse e incluso perderse. Esto se intenta evitar por medio de nuevas introyecciones, con el fin de hacerse con el valorado objeto y guardarlo dentro de sí, protegiéndolo también de la propia destructividad. Pero tal introyección coincide con un estado acusado de las pulsiones sádicas (canibalísticas), lo que conlleva nueva angustia por el temor a destruir lo que por otro lado se desea conservar. Surgen de aquí nuevos sentimientos depresivos, como el duelo, la nostalgia, la culpa y la desesperación en conexión a los daños o pérdidas del objeto.

Ahora bien, la posición depresiva supone así mismo la aparición de intensos procesos reparadores de lo destruido, procesos que nacen de la pulsión erótica y de la omnipotencia entonces presente, lo que aboca en una reconstrucción de los objetos internos y externos, debilitándose la escisión y la proyección, que se sustituyen por la represión, inhibición y desplazamiento, de modo que las defensas psicóticas ceden su lugar a las defensas neuróticas, lo que se ve muy favorecido por la aparición de la capacidad de simbolización.

La reparación es la defensa más positiva para que el desarrollo humano tome un camino sano, pues es el motor de la integración de los objetos externos e internos, del self, del yo, del superyó, etc. Al restaurarse el objeto, por ejemplo, se recupera la 
confianza en sí y pueden mantenerse unas relaciones gratificantes con el objeto amado, así como soportar el dolor que su inevitable desaparición periódica ocasiona, sin que nazca un odio abrumador, de modo que un aspecto importante de la reparación es aprender a renunciar al control omnipotente del objeto, asumiendo la realidad psíquica tal como es.

La reparación, sin embargo, puede tener un ingrediente maníaco, que supone una defensa, al contrario de la reparación no maníaca, ya que ésta implica el reconocimiento de la realidad psíquica, así como la aceptación del dolor que puede causar y la puesta en marcha de acciones adaptativas (en la realidad subjetiva y objetiva) para remediar lo negativo, renunciándose a la magia y a la omnipotencia. En cambio, la reparación maníaca busca resolver los sentimientos de culpa o las pérdidas del objeto por medio de la magia, la omnipotencia, la escisión, la excesiva dependencia, etc., sin que ello facilite el logro de una resolución permanente de la angustia.

Las defensas maníacas no afectan sólo a la reparación, sino a cualquiera de las defensas que ya se manifestaron a lo largo de la posición esquizoparanoide, como la escisión, la idealización, la identificación proyectiva y la negación, aunque en la posición depresiva todas ellas adquieren características más organizadas, estando dirigidas al control de la ansiedad depresiva. Como la vivencia de dependencia y ambivalencia alcanzan gran expresión en la posición depresiva, las defensas maníacas se dirigen fundamentalmente contra tales sentimientos, anulando, negando 0 invirtiendo la dependencia o exagerando la escisión del objeto, del self y del yo.

La relación maníaca con los objetos se caracteriza, por otra parte, por una tríada de sentimientos: control, triunfo y desprecio. En cuanto a controlar al objeto es una manera de negar la propia dependencia que se tiene respecto él; pero, al mismo tiempo, es una forma de obligarlo a satisfacer la necesidad de tal dependencia, ya que se puede contar con un objeto controlado. Respecto al triunfo, es la negación de los sentimientos depresivos ligados a las presuntas destrucciones, lo que viene acusado por la satisfacción de los fines que persigue la envidia primaria, el elemento más destructivo de la pulsión tanática. Finalmente, despreciar al objeto es negar cuánto se valora, lo que atenúa la tristeza y la culpa que conlleva su pérdida real 0 fantaseada (18).

Por otro lado, Melanie Klein y Anna Freud diferían radicalmente en la concepción del superyó: para Anna, el niño pequeño tiene un superyó muy débil, que se estructura tardíamente, mientras que para Melanie es precoz, severo y cruel, por lo que se impone su modificación profunda con un análisis reglado, evitando toda actuación pedagógica a modo de superyó auxiliar. En cuanto al momento de la instauración, Anna, que seguía las directrices de su padre, entendía que el superyó era una instancia relativamente tardía, fruto de la resolución del complejo de Edipo de la fase fálica, mientras que Klein sostuvo que su aparición era muy anterior, siendo el complejo edípico, en sus etapas tempranas, un resultado de su presencia y acción y no al revés. 
Klein observaba en sus pacientes infantiles, incluso de dos años de edad, culpas y remordimientos conectados a fantasías de carácter agresivo, derivando de aquí la idea de una presencia temprana del superyó, cuyas actuaciones eran sádicas y crueles. Primeramente defendió que ello era evidente a los dos años de edad y más tarde opinó que había signos de tales hechos tras el primer trimestre de vida, en el momento de empezar a estructurarse la posición depresiva, es decir, mucho antes de la fase fálica. Para Klein, pues, el superyó no es un derivado de la resolución del complejo de Edipo, sino uno de sus principales causantes, resaltando que sus características determinaban el desenlace de tal conflicto nuclear y por tanto del desarrollo del self, del carácter y de la conducta (24).

En Contribuciones a la psicogénesis de los estados maníaco-depresivos (19), Klein insiste en separar tajantemente el origen del superyó y la aparición del complejo de Edipo: el yo existiría desde el comienzo de la vida, formándose el superyó por la introyección de los objetos construidos por la fantasía infantil a partir de la relación con el objeto externo y de la proyección de las pulsiones erótica y tanática sobre él, así como de la paralela acción de la escisión.

Klein estimó que el inconsciente era como una especie de representación pulsional, de donde emergería la fantasía (phantasy) por la acción de un yo precoz, fantasía que acogía abundantes temáticas sádicas de penetración en el cuerpo de la madre, para satisfacer la curiosidad y los deseos de destruir (oral, anal o fálicamente) sus contenidos (heces, bebés y pene), con la subsiguiente culpa y ansiedad persecutoria (ser tratado según la ley del Talión por el objeto parcial persecutorio). Dicha ansiedad persecutoria conduciría a la búsqueda de alianzas con nuevos objetos, símbolos del cuerpo materno y de los contenidos fantaseados (heces, bebés y pene), simbolizaciones que serían los fundamentos del desarrollo cognitivo y de las relaciones con el mundo y la realidad (20).

La teorización en torno a la importancia de la pulsión tanática culminó con las ideas sobre la envidia primaria, que se consolidan en Envidia y gratitud (16), donde se mantiene la tesis de la existencia de una envidia innata del pecho materno, por ser fuente de vida y de experiencias gratificantes y además objeto idealizado, reservorio inagotable de todos los bienes y poderes. Frente a tal envidia describe Klein la gratitud innata (expresión de la pulsión erótica), de modo que ambos factores serían los máximos determinantes del desarrollo desde el mismo instante de nacer.

La envidia es distinguida por Klein de otros sentimientos y emociones cercanos, como los celos y la voracidad, sin negar por ello la posibilidad de su asociación. La envidia no la considera secundaria a la frustración con el pecho materno, sino una manifestación innata de la pulsión de muerte, cuya finalidad es atacar al objeto bueno y valioso, poniéndose paradójicamente en marcha cuando el niño siente que es gratificado por él: la envidia busca la posesión de las ideales cualidades del objeto bueno, $y$, si esto no es posible, destruirlo, porque no puede aceptarse ni tolerarse 
que lo bueno sea ajeno, aunque seamos los beneficiados. Los celos, en cambio, suponen un deseo de eliminar al rival que puede quitarnos la persona amada, implicando una relación triangular, incluyendo objetos totales, a diferencia de la envidia en la que basta una relación diádica, incluso con un objeto parcial. La voracidad, por último, busca extraer todo lo bueno del objeto, sin que el sujeto llegue nunca a satisfacerse, pudiendo asociarse a la envidia, llevando a la ruina y destrucción de dicho objeto.

La teoría de la envidia primaria trató de ser integrada a la teoría de las posiciones de la siguiente forma: si los impulsos envidiosos son intensos, se dirigen hacia la máxima fuente de la envidia, el objeto ideal. Esto altera el proceso de escisión normal que acontece en la posición esquizoparanoide, ocasionando una grave confusión entre lo bueno y lo malo, con las subsiguientes anomalías en las introyecciones e identificaciones de y con los objetos ideales, frenándose así el desarrollo normal al imposibilitarse la necesaria integración de los objetos parciales internos y de los objetos parciales externos, lo que impide el acceso adecuado a la posición depresiva.

La envidia puede movilizar una serie de defensas contra ella, como destruir totalmente al objeto envidiado, para así acabar con tal sentimiento; o bien desvalorizarlo (lo que de alguna forma lo preserva); o proyectar los sentimientos envidiosos en el objeto y superidealizarlo para hacerlo indestructible (aunque esto trae consigo aún más envidia). Frente a tales alternativas, la salida positiva tiene lugar si el amor y la gratitud son más potentes que la destrucción y la envidia, pudiendo ser atemperadas, lo que permite que el objeto ideal siga existiendo y pueda ser introyectado, favoreciéndose el desarrollo del yo y superyó. Sin embargo, según Klein siempre existirán restos de envidia, que se desplazarán en un momento dado desde el pecho materno al pene del padre, incrementando la rivalidad con éste; y ulteriormente a otros muchas personas que aparezcan en nuestra vida.

En lo referente al complejo de Edipo, inicialmente Klein (24) mantuvo que empezaría a dar la cara tras cumplir el niño los dos años de edad, para inclinarse finalmente por una etapa anterior, concretamente a partir de la primera mitad del segundo año de vida extrauterina, e incluso antes, como un producto secundario a la organización de la posición depresiva, de la que lo considera una parte integrante $(25,26)$.

Las secuencias del proceso edípico serían cuatro: a) una fase femenina, ocasionada tras la frustración del destete, que daría la cara en la primera mitad del segundo año de la vida; b) una fase masculina, producto de la represión de la fase anterior; c) una fase completa, con deseos incestuosos hacia la figura paterna de sexo contrario y odio o rivalidad respecto a la del propio sexo; y, d) una fase de resolución final, que, en los casos sanos, ocasionaría una identificación con el progenitor del mismo sexo y la búsqueda de relaciones amorosas no incestuosas con una persona de sexo contrario. 
El complejo de Edipo en la niña no se considera como una forma modificada e incompleta de tal complejo en el varón, como mantuvo Freud, sino un proceso con sus propias peculiaridades. Es más, en el caso del varón se describe una fase femenina, común a la primera fase de la chica, aunque con sus matices particulares.

Tales ideas obligaron a un replanteamiento de la metapsicología freudiana, tarea en la que Klein se empeñó con ahínco desde 1934 en adelante, organizando más y más sus teorías de las posiciones y de las relaciones objetales, en torno a las cuales se conjugan las siguientes hipótesis básicas (27): a) una nueva concepción del desarrollo temprano; b) una sustitución del concepto de fase por el de posición; c) una puesta en primer plano de la relación con los objetos; d) una acentuación de la importancia de la ansiedad; e) un claro dualismo pulsional, donde el Tánatos toma primacía sobre el Eros; y, f) una nueva delimitación de la fantasía inconsciente, como expresión mental de las pulsiones («instintos»).

\section{LAS I NNOVACIONES TÉCNI CAS DE MELANI E KLEI N}

En lo que se refiere a las aplicaciones en pacientes adultos, según Segal (33) el análisis freudiano y el kleiniano no presentan aparentemente diferencias llamativas en los aspectos formales: un similar encuadre, proporcionando al paciente cinco 0 seis sesiones semanales, de cincuenta minutos de duración, estando aquél tendido en el diván con el analista tras él, respetándose las reglas tradicionales (asociación libre, atención flotante, neutralidad y abstinencia) e interpretándose el material que surge de las asociaciones libres (29). Ahora bien, cuando se acerca uno al trabajo que se lleva a cabo dentro de uno y otro encuadre, hay algunos distanciamientos entre ambas perspectivas: así, por ejemplo, las interpretaciones de los kleinianos son muy precoces y se centran en las ansiedades tempranas y defensas que las rodean, que se expresan en el aquí y ahora de la situación transferencial, sobre todo en su cara negativa. Los kleinianos intervienen en tales fenómenos, además, incluso desde la primera sesión, aunque sin tocar las defensas yoicas estructuradas. Esto se hace así para evitar descompensaciones, que aparecerían al dejar al sujeto sin tales defensas.

En el caso del análisis infantil, los analistas kleinianos son aún más peculiares, pues el niño juega con ciertos elementos preparados ad hoc, interpretándose tal actividad y las verbalizaciones y dibujos que la rodean de forma semejante a como se hace con los adultos, pero a la luz de la teoría kleiniana de las relaciones objetales, teniendo en cuenta los fenómenos descritos en las posiciones esquizoparanoide y depresiva. El contenido de las interpretaciones posee, así, unos ingredientes acordes con tales fenómenos, lo que se parece poco a lo que efectúan los freudianos, más centrados en las temáticas edípicas evolucionadas.

A la luz de su perspectiva sobre la fantasía, las tradicionales resistencias del yo son conceptualizadas por los kleinianos como defensas contra la penetración del 
analista, interpretándose sólo los contenidos de las ansiedades persecutoria y depresiva y las defensas precoces que se expresan en las fantasías verbalizadas o que están implícitas en los juegos y otras actividades, observables en las distintas sesiones, dejándose indemnes las defensas posteriormente organizadas, pues se estima que éstas irán diluyéndose conforme se neutralizan las ansiedades psicóticas (persecutoria y depresiva) (28).

Los kleinianos mantienen, pues, que los fenómenos transferenciales ponen ante el terapeuta, con una expresión directa en el niño y más elaborada en los adultos, las conflictivas precoces con los objetos internos, fruto de la fantasía inconsciente, interesando analizar las relaciones e interinfluencias entre dicha fantasía y la realidad externa. Con esta forma de proceder, según ellos, no se deja al yo sin protección, por lo que puede trabajarse con niños y con psicóticos, todos ellos portadores de un yo en formación o muy débil.

En sus análisis, tanto en el caso de adultos como de niños, además, los kleinianos se atienen a interpretar el estrato en que se muestra la ansiedad, teniendo en cuenta su intensidad, procurando rastrear las fuentes pulsionales originales, poniendo en evidencia los estadios más primitivos del complejo edipiano, buscando facilitar el correcto establecimiento y superación de la posición depresiva, ayudando a la integración de las partes escindidas de los objetos, del self y del yo, superando así los restos de angustia paranoide y de culpa depresiva. En concreto, cuando Klein formuló su teoría de la posición depresiva, nos dijo que la cura implica la translaboración de esta posición y cuando fijó los criterios para la terminación de un análisis (29), afirma que el tratamiento finaliza cuando han sido suficientemente disminuidas las ansiedades y culpas paranoides y depresivas mediante la elaboración profunda de las fantasías implícitas en las posiciones psicóticas, permitiendo ello que las relaciones con el mundo interior y con el mundo exterior queden lo suficientemente fortalecidas, de modo que el sujeto puede tratar de modo satisfactorio con la realidad psíquica subjetiva y objetiva.

Por todo lo dicho, existe, a nuestro entender, una total conformidad entre las construcciones teóricas kleinianas y la técnica correspondiente: lo esencial está en la interpretación de las fantasías expresadas en las sesiones con el fin de que el sujeto logre la comprensión profunda de su realidad psíquica, poblada de ansiedades psicóticas y defensas contra ellas, fantasías que se ponen en marcha por la acción del yo sobre la pulsión erótica y la pulsión tanática, que se dirigen hacia los objetos internos y externos. No caben aquí las medidas de apoyo, el recurrir a las porciones sanas del yo o cualquier otra intervención que pueda abocar en la disociación de los aspectos amorosos y hostiles. El analista ha de respetar estrictamente la neutralidad y la abstinencia, aceptando las proyecciones del sujeto y el clima emocional que esto implica, teniendo que estar en condiciones de devolver, con sus interpretaciones, lo que las identificaciones proyectivas, las ansiedades psicóticas y las correspondientes 
defensas precoces conllevan. Ahora bien, en un momento dado, Klein (30), aunque insistió en que las interpretaciones deben permitir la comprensión profunda de las primitivas relaciones objetales que se expresan en la situación transferencial, también señaló que debían analizarse las fantasías inconscientes que el paciente pone en marcha en su vida actual más allá del aquí y ahora de la sesión, lo que supera posturas que sostuvo con anterioridad.

En lo referente a la contratransferencia, Klein no utilizó inicialmente este concepto, e incluso cuando un analista hablaba de ella, decía que no estaba suficientemente analizado. Cada sesión la entendía como una situación total relacionada con el analista, que se considera un representante de los objetos internos y externos del paciente. El analista ha de dejarse envolver por el clima emocional que emana de su analizado, debiendo ser receptor de todas las proyecciones que éste ponga en marcha, dejando absolutamente de lado los presuntos elementos contratransferenciales. Sin embargo, en la identificación proyectiva late de alguna forma la idea de contratransferencia, pues tal concepto supone que el paciente deposita una porción de su realidad psíquica en el analista, pasando éste a ser una parte de su self, pudiendo acontecer que el analista quede atrapado en tal situación, sin poder salir de ella, idea que mantuvo Heimann $(31,32)$. Por consiguiente, el analista, aun involucrándose emocionalmente en lo provocado por tal defensa, ha de adoptar una actitud lo suficientemente neutral y objetiva para devolver adecuadamente al paciente lo proyectado, lo que exige contar con la contratransferencia, para poder controlarla. Quizás por todo ello en Envidia y gratitud, Klein (16) llega a admitir de forma más explícita la importancia de la contratransferencia, aunque sin darle el papel de sus discípulos y seguidores.

\section{ALGUNAS CRÍTICAS A LA DOCTRINA KLEI NI ANA}

La metapsicología freudiana tiene la teoría pulsional como su núcleo esencial, así como la paralela teoría del conflicto intrapsíquico. En este marco, se torna fundamental la idea de la descarga de la energía psíquica, apareciendo el objeto y las relaciones con él secundaria y tardíamente. La perspectiva kleiniana rompe con tal visión, pues son los vínculos y no las pulsiones los responsables del desarrollo normal y de la enfermedad mental psicógena.

Sin duda, tal propuesta es meritoria, dado que enriquece el modelo interactivo en la explicación de la conducta humana. Pero también hay un demérito: el haber creado una teoría genética general desde presupuestos clínicos y con datos a veces de naturaleza patológica, error de alguna forma semejante al que cometió Freud, sin que podamos estar seguros de que efectivamente acontecieron en la realidad objetiva 0 subjetiva en el momento en que se sitúan y en la forma en que se expresan (27). También puede argumentarse, como crítica, si no hay proyección de los propios con- 
flictos del terapeuta, o de la misma construcción teórica que defiende, sobre los hechos conductuales que se registran en el paciente, pudiendo ser tales fenómenos susceptibles de hipótesis explicativas distintas.

En otro orden de cosas, Klein da excesiva primacía, en el desarrollo y en la psicopatología, al papel de lo constitucional e innato, sin que cuente en la debida medida con la influencia de la experiencia con la realidad externa: tanto los objetos externos como los internos se construyen más por temáticas que presuntamente están en la mente del niño que por las actuaciones de tales objetos, lo que alcanza su máxima expresión con la teoría de la envidia y la gratitud innatas. Esta forma de entender el desarrollo no es bien acogida por la actual psicología, muy sensibilizada a lo ambiental, cuestión que algunos de los seguidores de Klein intentarán resolver.

Es también chocante, dado el conocimiento que poseemos sobre el funcionamiento cognitivo del bebé, atribuirle la complejidad que Klein le supone, dando en ocasiones la impresión de que ésta asume la teoría platoniana de las I deas o Formas, en versión más o menos cartesiana. En ocasiones parece que Klein proyecta en la mente infantil lo que pudiera existir en la suya, de tal forma que terminó encontrando lo que estaba en su cabeza.

Por otra parte, se intuyen excesivos valores normativos, y concretamente judeocristianos, en la teoría kleiniana, dando la impresión de que la reparación posee connotaciones ligadas con la superación del pecado original, 0 , en general, del mal (envidia) por la acción del bien (gratitud). Al respecto, Laing (33) ha escrito que Envidia y gratitud es una teología sin Dios. Tal elemento ideológico-filosófico, sin duda respetable, es ajeno a la ciencia, pareciendo más bien que Klein se ha dejado influir por sus problemáticas y por sus raíces judías, más que por los hechos.

En lo que toca a la técnica kleiniana, ha sido estimada por algunos como brusca y desconsiderada, insistiéndose en que las interpretaciones que se usan son adoctrinadoras y se viven por el analizado como seducciones 0 agresiones, con la consiguiente contaminación de los estrictos fenómenos transferenciales. Laing (33) resalta que, al ponerse excesivo acento en la ansiedad, termina intensificándola, creando una fuerte dependencia del analizado respecto al analista que se prolonga indefinidamente. Los críticos subrayan, además, que el paciente sólo tiene acceso a un conocimiento intelectual, dada la utilización de interpretaciones muy profundas y simbólicas sin la debida disolución de las resistencias yoicas: los analizados, se ha llegado a decir, terminan sabiendo lo que les pasa, pero continúan con sus síntomas y problemas.

Para superar las objeciones a la técnica, los poskleinianos han llevado a cabo ciertas modificaciones en la misma, aunque conservando lo esencial de los fundamentos teóricos de Klein, esto es, la importancia de los conflictos psíquicos tempranos en relación con el objeto, la teoría de la angustia, el papel de la pulsión de muerte, de los celos y de la envidia frente a la escena primaria, etc. (34). Sin embargo se ha 
pulido bastante la práctica, insistiéndose en la necesidad de lentificar el ritmo, pausando el trabajo interpretativo de modo que no se ataquen las fantasías tempranas sin considerar antes lo que sucede en aspectos históricamente más cercanos, que también dan la cara en la relación transferencial. El analista, además, adopta la función de continente señalada por Bion (35) respecto a las ansiedades del paciente, Ilamándose la atención sobre la enorme importancia de la contratransferencia a la hora de la interpretación $(31,32,36,37)$. Por otra parte, el grupo británico ha dado al analista un papel que va más allá del de mero continente de ansiedades, insistiéndose en que debe proporcionar un sostén (holding de Winnicott), con una especie de amor maternal empático, para favorecer, tras la regresión que ocasiona el encuadre clínico y el proceso de la cura, un nuevo nacimiento (new beginning de Balint), experiencia que lleva consigo la organización de la serie de autocomprensiones (insights) que el sujeto ha podido experimentar a lo largo de su análisis.

\section{BIBLIOGRAFÍ A}

1. Hinshelwood, R. D. Diccionario del pensamiento kleiniano. Buenos Aires: Amorrortu, 1992.

2. Hug-Hellmuth, H. «On the Technique of Child Analysis». International J ournal of Psycho-Analysis, 1922, 2, 287-302.

3. Klein, M. Simpósium sobre análisis infantil. En Obras Completas, 1. Barcelona: Paidós, 1989, 148-177.

4. Isaacs, S. La naturaleza y función de la fantasía. En M. Klein y otros, Desarrollos en psicoanálisis. Buenos Aires: Hormé, 1967.

5. Klein, M. Principios psicológicos del análisis infantil. En Obras Completas, 1. Barcelona: Paidós, 1989, 137-147.

6. Freud, A. Psicoanálisis de niños. Buenos Aires: Paidós, 1977.

7. King, P. y Steiner, R. Las controversias Anna Freud-Melanie Klein (1941-1945). Madrid: Síntesis, 2003.

8. Grosskurth, P. Melanie Klein. Su mundo y su obra. Barcelona: Paidós, 1990.

9. Petot, J. M. Melanie Klein. Primeros descubrimientos y primer sistema (19191932). Buenos Aires: Paidós, 1982.

10. Lindon, J. A. Melanie Klein. En J. Spanjaard y otros, Historia del psicoanálisis V. Buenos Aires: Paidós, 1968, 67-85.

11. Klein, M. El desarrollo de un niño. En Obras Completas, 1. Barcelona: Paidós, 1989, 15-65.

12. Arnoux, D. J. Melanie Klein. Vida y pensamiento psicoanalítico. Madrid: Biblioteca Nueva, 2000.

13. Klein, M. El psicoanálisis del niño. En Obras Completas, 2. Barcelona: Paidós, 1987, 19-290. 
14. Geissmann, C. y Geissmann, P. Histoire de la psychanalyse de I=enfant. Paris: Paidos/Bayard Éditions, 1992.

15. Glover, E. El psicoanálisis en Inglaterra. En Ch. W. Whal y otros, Historia del psicoanálisis VII. Buenos Aires: Paidós, 1968, 57-74.

16. Klein, M. Envidia y gratitud. En Obras Completas, 3. Barcelona: Paidós, 1988, 181-240.

17. Klein, M. La técnica psicoanalítica del juego: su historia y significación. En Obras Completas, 3. Barcelona: Paidós, 1988, 129-146.

18. Segal, H. Introducción a la obra de Melanie Klein. Buenos Aires: Paidós, 1984.

19. Klein, M. Sobre la teoría de la ansiedad y la culpa. En Obras Completas, 3. BarceIona: Paidós, 1988, 34-51

20. Klein, M. Contribución a la psicogénesis de los estados maniaco-depresivos. En Obras Completas, 1. Barcelona: Paidós, 1989, 267-295.

21. Klein, M. El duelo y su relación con los estados maniaco-depresivos. En Obras Completas, 1. Barcelona: Paidós, 1989, 346-371.

22. Grotstein, J. S. I dentificación proyectiva y escisión. Buenos Aires: Gedisa, 1983

23. Klein, M. Notas sobre algunos mecanismos esquizoides. En Obras Completas, 3. Barcelona: Paidós, 1988, 10-33.

24. Klein, M. Estadios tempranos del conflicto edípico. En Obras Completas, 1. BarceIona: Paidós, 1989, 193-204.

25. Klein, M. La importancia de la formación de símbolos en el desarrollo del yo. En Obras Completas, 1. Barcelona: Paidós, 1989, 224-237.

26. Klein, M. El complejo de Edipo a la luz de las ansiedades tempranas. En Obras Completas, 1. Barcelona: Paidós, 1989, 372-421.

27. Bleichmar, N. M. y Leiberman,C. C. El psicoanálisis después de Freud. Teoría y clínica. Buenos Aires: Paidós, 1989.

28. Segal, H. La técnica de Melanie Klein. En B. B. Wolman (dir.), Técnicas psicoanalíticas. Buenos Aires: Troquel, 1972, 233-261.

29. Klein, M. Sobre los criterios para la terminación de un psicoanálisis. En Obras Completas, 3. Barcelona: Paidós, 1988, 52-56.

30. Klein, M. Los orígenes de la transferencia. En Obras Completas, 3. Barcelona: Paidós, 1988, 57-65.

31. Heimann, P. «On Countertransference». International J ournal of Psycho-Analysis, 1950, 31, 81-84.

32. Heimann, P. «Countertransference». British J ournal of Medical Psychology, 1960, 33, 9-15.

33. Laing, R. D. El yo dividido. México: Fondo de Cultura Económica, 1964.

34. Sutherland, J. A. «The British Object Relations Theorist: Balint, Winnicott, Fairbairn, Guntrip». International J ournal of Psycho-Analysis, 1980, 50, 317-333.

35. Bion, R. Elementos del psicoanálisis. Buenos Aires: Paidós, 1966. 
36. Racker, H. «Una contribución al problema de la contratransferencia». International J ournal of Psycho-Analysis, 1953, 34, 313-324.

37. Racker, H. Estudios sobre técnica psicoanalítica. Buenos Aires: Paidós, 1977.

Antonio Sánchez-Barranco Ruiz

Reyes Vallejo Orellana

Facultad de Psicología de la Universidad de Sevilla

$\mathrm{Cl}$. Camilo J osé de Cela, s/ $\mathrm{n}$.

41018 Sevilla 